\title{
The Culture of Retirement in Lebanon: Obstacles and Opportunities for Addressing the Transition to Public and Private Sector Post- Employment Life
}

\begin{abstract}
ID Zeina Chemali' ID Nellie Shippen² ID Romy Nehme ${ }^{3}$ ID Christina Borba ${ }^{4}$
Abstract

Retirees in Lebanon currently experience a number of socio-cultural and economic obstacles that limit their ability to experience retirement in a meaningful and productive way. The current paper draws on research and programming in Lebanon that was developed to understand and promote a healthy culture of retirement in Lebanon where the needs of retirees were explored by a joint initiative by the government and civil society. Results of two focus groups and the implementation of community enrichment pilot programs for retirees fed into the development of a framework to highlight the ways in which investments in retirees could be optimally realized at the national and municipal levels in Lebanon. Future plans for research and programming to test this model further were also generated as part of this overall project. These results provide a framework for how retirees may be further engaged in civil society and a roadmap for conceptualizing programs for retirees that need minimal large-scale government action.
\end{abstract}

Keywords: Retirement, social support, social norms, culture, intervention, Lebanon

\section{Key Practitioners Message}

$>$ This may be a beneficial model for those practitioners working in countries in middle income and post-war transitional phase governments where significant legislative commitments to retirees may be slow to enact.

\section{Introduction}

The nature of retirement and the role retirees play in society is an economic, cultural, and social issue that governments around the world often face. In middle and low-income countries, ensuring the financial security with high quality of life in the community for retirees has become increasingly challenging (Rached, 2012; Tohme, Yount, Yassine, Shideed, \& Sibai, 2011); increased life expectancy, a growing proportion of retirees in the population, and the economic burden of providing robust social security benefits and pensions to retirees are active issues.

Lebanon has experienced pronounced obstacles to supporting retirees due to a number of demo- graphic factors, including an aged population (mainly women) coupled with an outdated social insurance system (Sibai, Sen, Baydoun, \& Saxena, 2004). This has left the country in need of economic, social, and societal reforms. Many retirees live alone ( $17.3 \%$ men and $6.2 \%$ women) and they end up with a meager income in old age, with $74.8 \%$ of their income supplied by their children (Tohme et al., 2011), vulnerable to falling into poverty with over half of Lebanon's older adults population considered "economically deprived" (Rached, 2012). This prevalent poverty status among older adults contributes to their deprivation from access to health services, water, electricity, and housing (Rached, 2012). Saxena (2008) asserted that

\footnotetext{
Correspondence: Zeina Chemali. 15 Parkman Street Wacc 81502114 Boston - United States. e-mail: zelchemali@partners.org Authors: ${ }^{1}$ Massachusetts General Hospital, Harvard Medical School, Boston

University of Illinois at Chicago, Chicago, Illinois

${ }^{3}$ Cambridge Health Alliance, Harvard Medical School, Boston

${ }^{4}$ Boston University School of Medicine, Department of Psychiatry, Boston 
the burden of supporting Lebanese pensioners would increase from $10.8 \%$ in 2000 to over $27 \%$ in 2050. To add to their struggle, the aftermath of the July 2006 War resulted in older adults as the most vulnerable population having more severe difficulty in attaining their needs (Sibai, Yount, \& Fletcher, 2007). This is due to the current system not attending to the needs of Lebanese adults older than 65, including retirees, and that the political situation does not allow for any foreseeable reform (Saadeh \& Mikhael, 2016; Sibai, 2000; SSA: Social Security Administration, 2010). The local and foreign institutions have proposed to institute a non-contributory social security scheme to counteract this troubling economic reality (Rached, 2012). Unfortunately, to date, no government propositions have been realized (Table-1).

This paper turns to other types of governmental and civil support that may not be monetary but rather based on educating, socially valuing, empowering, and better understanding retirees. These resources and supports begin with providing aid to retirees in financial planning as they age, such as covering benefits, pension plans, health and continued education as well as developing projects for retirees to contribute productively to society and their local community. These are also resources and programs that with cultural adaptations, may provide frameworks for countries outside of Lebanon navigating similar issues with their population of retirees to implement.

This paper will introduce the "culture of retirement," a concept very new to the Lebanese population. The culture of retirement is likened to an educational pedagogy where we need to gain knowledge and culture to understand it and have it prosper. We write with the hope that this conceptual framework will be utilized, revised, and practiced to serve the needs of diverse Lebanese communities. Like any new concept, it remains in its nascent form and will need multiple iterations through evaluation and monitoring to understand what works and what does not. The core structure of this model may also serve as a template for other communities to develop their own national or community-specific paradigms.

\section{Literature Review}

Lebanon is a country in the Middle East located in the Eastern Mediterranean. It has a population estimated at 6.86 million, though no official census has been conducted since 1932. The population pyramid favors youth with citizens younger than 54 years of age, constituting $84 \%$ of the population. Having said that, the portion of the population 55-64 years of age accounts for $8.34 \%$ of the total population (241.206 males; 267.747 females) and people aged $>65$ years of age as 7.03\% (185.780 males; 243.015 females), numbers that are on the rise (Sibai et al., 2004; SSA, 2010). Twenty-five percent of the Lebanese population lives below the poverty level (ReliefWeb, 2017). Despite this predicted rise in population demographics and increased financial insecurity, little research has taken place in Lebanon to gauge the climate of retirement in the country.

Recent protests took the streets demanding for equality and the end of corruption (BBC, 2019). Many were demanding reforms in all sectors, including urgent retirement reforms and end-ofjob security. $28 \%$ of Lebanon's 1.5 million healthy workforces are covered by a 1963 pension law. $80 \%$ of Lebanon's population aged $>65$ years of age lacks pension and health coverage, as most have worked in the informal economy or private sector (ILO: International Labor Organization, 2013). The remaining $20 \%$ of workers are from the public and military sectors and have their own retirement scheme (SSA, 2010). The social security in Lebanon is regulated by an outdated law of 1963, which provides for a social insurance system granting end-of-service indemnity (EOSI) lump-sum benefits only with no further security benefits. There is no monthly payment, and all benefits, including health coverage, end at retirement (Abdulrahim, Ajrouch, \& Antonucci, 2014; Rached, 2012; The Presidency of the Council of Ministers, 2019). The system covers employees in the industry, commerce, and agriculture sectors. Public sector employees and teachers are covered by a separate system. The employers contribute solely to the fund constituting $8.5 \%$ of the payroll, leaving a real strain on employers also at the end of service as they must muster a large 
sum when the employee retires (Rached, 2012). The insured person does not have to make any contribution. The old-age benefit is available from age 60 but is compulsory after 64 .

This benefit consists of a lump sum of the final month of earnings (or one month of average monthly earnings during the previous twelve months, if higher) multiplied by the number of years of service up to 20 years plus 1.5 months of earnings per year of service beyond 20 years or up to age 64 (The Presidency of the Council of Ministers, 2019) (Table-1). Public pensions make up 3\% of Lebanon's Gross Domestic Product (GDP) and operate on the pay-as-you-go system. The most recent pension increase was granted in 2012. In 2017, a new bill to compensate for the increase in salary and new pension plans for a salary increase was complicated by a tax hike and was debated in parliament (The Daily Star, 2017).

The NSSF currently operates in the private sector and helps provide end of service pension plans, covers sick leave, maternity leave, portions of medical care, and a handful of additional service benefits that are only available to working members of society employed in the private sector and who are insured (SSA, 2010). Most individuals working in the private sector (excluding those who are self-employed) rely on the NSSF for end of service benefits (Jarmuzek \& Nakhle, 2016; SSA, 2010). The National Social Security Fund (NSSF) and additional private sector social security schemes also do not address the financial needs of those who have never been employed, a demographic in Lebanon primarily comprised of women (Abdulrahim et al., 2014) (Table-1).

With this scheme above, Lebanon is one of the shrinking minority of countries that maintain EOSI (Sibai, 2000). In comparison, other countries in the region such as Jordan, UAE, Syria, Iraq, and Saudi all cover regular pension. Moreover, in comparison to low-income countries in the African continent, Lebanon continues to fall behind in services offered and reforms enacted to meet the needs of its retirees. Uganda (population 42.86 million) covers $10.2 \%$ of its total workforce and allows for a pension plan, annuity, and lump sum (Munyam- bonera, Katunze, Munu, \& Sserunjogi, 2018). In fact, in 2018, Uganda had to expand pension coverage as retirees' numbers increased, and the coverage was uneven (Munyambonera et al., 2018). In another example, Rwanda (population 12.21 million) maintained a social security law framework since 1956 with reformed laws in 1974, 2003 and 2015 for their national pension scheme. Salaried workers (temporary and casual), professionals, trainees, civil servants, politicians and government employees in Rwanda are all covered. Even self-employed citizens have voluntary coverage of up to $50 \%$. The employee starts with $3 \%$ of covered earnings and can go up to $30 \%$ after 3 years while the employer covers $3 \%$ of payroll. At the end of employment, the retiree is offered a lump sum in addition to a monthly pension. There is even a disability coverage, sickness and maternity coverage as well as survivor pension. In 2016, Rwanda enacted a new reform to cover self-employed women, often in agriculture and small-scale artisans, in their maternity security coverage as well as end-of-work indemnity (SSA, 2017).

There is no doubt that Lebanon could gain a great deal from reviewing its own law and moving towards the acceptable global reality when it comes to social security. Many reform proposals have been drafted, essentially to transform the lump sum payment, which is rapidly spent when citizens need it most to cover healthcare and other expenses, into a monthly pension for the remainder of their lives as it will be best for the retirees and also easier on the employers. In 2004, the government proposed a flat indemnity for the public sector to individuals who have not worked enough and a minimum pension for those who had enough contributions (Rached, 2012). In 2011, there was another new draft which promoted individuals to pay a contribution from their salaries and receive at least $40 \%$ of their wages if they have worked for more than 30 years (ILO, 2013). World Health Organization (WHO) also proposed an investment policy to increase the monthly contributions and get; as a result of a monthly lifetime pension under ethical principle to protect and "senior citizens have the right to be fully insured" (Hamade, Ghobeira, \& Yassin, 2015). 


\begin{tabular}{|c|c|c|}
\hline & PUBLIC SECTOR & PRIVATE SECTOR \\
\hline Retirement Age & $\begin{array}{l}\text { Maximum retirement age } 64 \text { for civil servants } \\
\text { Maximum retirement age } 58-64 \text { for military members } \\
\text { depending on military rank. }\end{array}$ & $\begin{array}{l}\text { The maximum age is } 64 \text { for eligibility to accrue } \\
\text { end of service indemnity. }\end{array}$ \\
\hline Benefits & $\begin{array}{l}<20 \text { years service receives an end of service payment } \\
>20 \text { years service received choice between lifetime } \\
\text { pension of end of service payment } \\
>40 \text { years service receives both a lifetime pension and } \\
\text { end of service payment } \\
\text { Dependents can inherit pension upon death of the em- } \\
\text { ployee }\end{array}$ & $\begin{array}{l}\text { Once the end of service indemnity is claimed, re- } \\
\text { tiree received lump sum totally one month's worth } \\
\text { of salary for every year worked, and } 1.5 \text { month's } \\
\text { worth of salary for every subsequent year worked } \\
\text { after } 20 \text { years. The downfall is that they lose all } \\
\text { benefits, including health services, after retire- } \\
\text { ment }\end{array}$ \\
\hline Contributions & $\begin{array}{l}6 \% \text { of basic salary; retirees do not have to contribute } \\
\text { during retirement }\end{array}$ & $\begin{array}{l}\text { Employees do not contribute. Employers contrib- } \\
\text { ute } 8.5 \% \text { of employees taxable income }\end{array}$ \\
\hline Exceptions & & $\begin{array}{l}\text { University teachers, private school teachers, and } \\
\text { private syndicates have alternative or additional } \\
\text { retirement schemes }\end{array}$ \\
\hline
\end{tabular}

\section{Collaborative Framework for a Proactive Initiative}

With little meaningful research and difficulties in delivering a developed contemporary policy for retirees in Lebanon, we joined efforts with the Lebanese Ministry of Social Affairs (MOSA) to explore alternative avenues to empower retirees and value their contribution to Lebanese society. MOSA assumes a pivotal role in developing the older adults' welfare pension scheme and has the power to solidify partnerships with United Nations Development Programs (UNDP) for pieces of training and more. Other stakeholders for such programs have been historically International Labor Organization (ILO), the World Bank, Ministry of Finances, and Ministry of Labor, NGOs, civil society, media, senior citizens. Our collaborative project aimed to develop a richer and more nuanced picture of the nature of retirement in Lebanon. A primary aim of the study was to determine what additional social, cultural, health, and economic factors hindered retirees in Lebanon and what concrete steps could be taken to incentivize greater political and community investment in retirees. These recommendations were then presented in a larger framework with the potential benefits of a new social contract between Lebanese retirees and civil society.

\section{Research Design and Methodological Ap- proach}

\section{Overview}

In December of 2013, two focus groups were conducted with retired civil servants in Beirut by the first author upon an invitation from the Lebanese Ministry of Social Affairs (MOSA). The focus groups provided insight on a variety of challenges faced by retirees and possible mechanisms for creating a healthy culture of retirement beyond increased pensions or social security benefits. The focus groups comprised of individuals from diverse Lebanese regions. Their responses were then adapted to set a pilot plan exploring what could be done to disseminate a healthier retirement culture in Lebanon. This initial endeavor included new opportunities for education, community development programs in the six municipalities of the country, fundraising, and a retiree appreciation day. Of note, the six municipalities volunteered to take part in the pilot program. As MOSA serves all Lebanese, it always divides its fieldwork and projects to cover 6 mohafazat (counties).

\section{Focus Groups}

The two focus groups were comprised of a total of 30 participants; $n=18$ in one group $n=12$ in the second (Figure-1). Members of the focus groups 
were retired civil servants and military members convened by MOSA in Beirut. The two groups were both heterogeneous in age, socioeconomic status, and religion. All participants but one were men. An interview guide was developed to probe for challenges facing retirees in Lebanon and how an ideal culture of retirement could be implemented in the country.

\section{Programming}

With data gathered in the focus group and after participants' consent given to MOSA organizers for the dissemination of the results of the focus groups, retirees from the public and private sector, NGO donors, experts on aging and finances, and municipal councils set to explore and test multiple approaches to improve retirement culture in Lebanon.

\section{Results of the Focus Groups}

Retirees in the focus groups generated a number of challenges they felt were most salient in characterizing the lack of retirement culture in Lebanon.

\section{Challenge 1: Inactivity of the Government}

Members of the focus groups felt that the primary responsibility for facilitating efforts to serve retirees in Lebanon was with the government. Both focus groups described the government's current role as "idle" and that "the government offers no support" with respect to its stance on aiding retirees. While policy reforms by the government had been enacted in the past, before the start of the civil war in 1975, the retirees felt that these reforms were often not realized in the community. No bills of this nature have been brought to parliament to vote on, especially as the country continues to be divided along sectarian lines and has never made it out of a post-war transitional phase to a stable good governance phase. Since 2013, there has been a public slogan that the social protections enacted through a robust and equitable pension plan is within reach (ILO, 2013). Unfortunately, this plan has not transpired.

Retirees in the focus group stated that some way to monitor government implementation of poli- cies toward retirees was critical for building their trust. A "watchdog" group to oversee external supervision of the government would also need to include retirees. It was also a desire of the retirees to see that these social policies from the government were sustainable and could remain enacted in the long term. One participant in the focus groups stated that "a bill with new rights" for retirees would be an essential next step to achieve this.

\section{Challenge 2: Lack of Financial Planning Resources}

A significant worry for retirees, per the focus groups, was that there are few resources in Lebanon for retirees to learn how to be financially savvy and independent after they no longer work. As one participant stated, "it is helpful to get training to prepare for this new phase, but no one offers anything." Courses on financial planning, wealth management, navigating inheritances, and family responsibilities in retirement were suggested as a way in which retirees could better prepare for the economic challenges engendered by the current system.

Moreover, Lebanon is seeing a prominent migration of working individuals to other countries. It is currently estimated that there is a more significant Lebanese diaspora than the current population of Lebanon (Abdulrahim et al., 2014). Traditionally, working family and community members have played a direct role in assisting retirees. However, the shifting demographics of Lebanese society leave many retirees to navigate the management of their finances alone and without many resources for preparation and guidance. The government may not be able to provide support to retirees through the more substantial end of service payments. However, it could improve the quality of their transition into retirement by providing the tools needed to manage their finances better and think early on to include education to their financial future throughout their productive working years.

\section{Challenge 3: Gender}

In the current generation of retirees in Lebanon, most women have not worked and therefore are 
not eligible for even the meager financial benefits provided at the end of service for workers in the private sector. The focus groups noted that any meaningful social policy enacted by the government for retirees needs to accommodate the current reality where men and women retire differently (Sibai, 2000; Sibai et al., 2004; Sibai et al., 2007). Traditionally, women who have not worked are not supported by the NSSF end of service indemnities, private syndicate schemes, or pension plan of a spouse. Unfortunately, public sector pension plans are the only schemes that ensure a worker's pension will pass on to a surviving spouse if the retiree dies (Jarmuzek \& Nakhle, 2016). For women of retirement age, factors such as childbirth and family life have often prevented even those women who have worked in their lifetime from being employed the number of years needed to receive maximum NSSF or pension benefits. According to the Lebanese League of Women in Business, over 15 pieces of legislature and amendments to the legislature as of 2011 have specifically aimed to add benefits for Lebanese women workers or to make their access to benefits more equitable to male counterparts. To date, almost all proposed items are "pending follow-up by the Lebanese Parliament" (MENA Group: World Bank Middle East and North Africa Social and Economic Development Group, 2009).

\section{Challenge 4: Lack of Appreciation}

Not all problems with the current culture of retirement in Lebanon discussed by the focus group were financial. Retirees stated that their psychosocial needs were not being met and that these too were requirements for a meaningful retirement culture. There was a general feeling among members of the focus groups that retirees were underappreciated by the government. Retirees viewed their experience in the community, their desire for productivity, and the years of investments made in them by the government while working to be an untapped resource. One participant described that "one should not surrender to retirement but should have a project." Rather than an idle period, the retirees viewed retirement as another phase in the "continuum" of their productive lives. Posi- tive cultural recognition of retirement and retirees was a necessary ingredient for any social contract between them and the government. However, the resources needed to galvanize such efforts, such as money and governmental support, were lacking.

\section{Challenge 5: Former Millitary Members Disengaged}

How retirement in the military field should be better addressed was a primary concern for the focus groups. When individuals are active in their military careers, the government of Lebanon invests heavily in their professional development. These career investments include receiving rigorous training locally and abroad. Retirees from the army thus felt dismayed by the sense of feeling severed from the military at the end of their careers. One participant in the focus groups described that once retirement begins, "we leave and vanish into thin air." After the resources that had been provided for their career development, the former military members of the focus group stated that they wished to both give back to the military through other forms of service. Instead of being "retired" from the military, a more favorable term posited by the focus groups was an "end of service." (Figure-1).With this background in mind, the outcomes from the focus groups centered on the new initiatives detailed below.

\section{Day of the Retiree}

On the national level, a Retiree Loyalty day was planned by MOSA and celebrated June 2, 2015, at the United Nations Educational Scientific and Cultural Organization (UNESCO) palace. Additional sponsorship also was provided by Lifeline and First National bank. There were 264 participants, among them 179 retirees who were involved in the municipality planning, 42 retirees from the public sector, and six retirees from the National Commission of the Elders. Many people were honored, and the event made national news. A pledge ensued to keep the celebration on a yearly basis in the period of May-June. Retirees on the planning committee wanted to connect to other groups worldwide to brainstorm and learn about how other nations promote an active, fruitful, and 


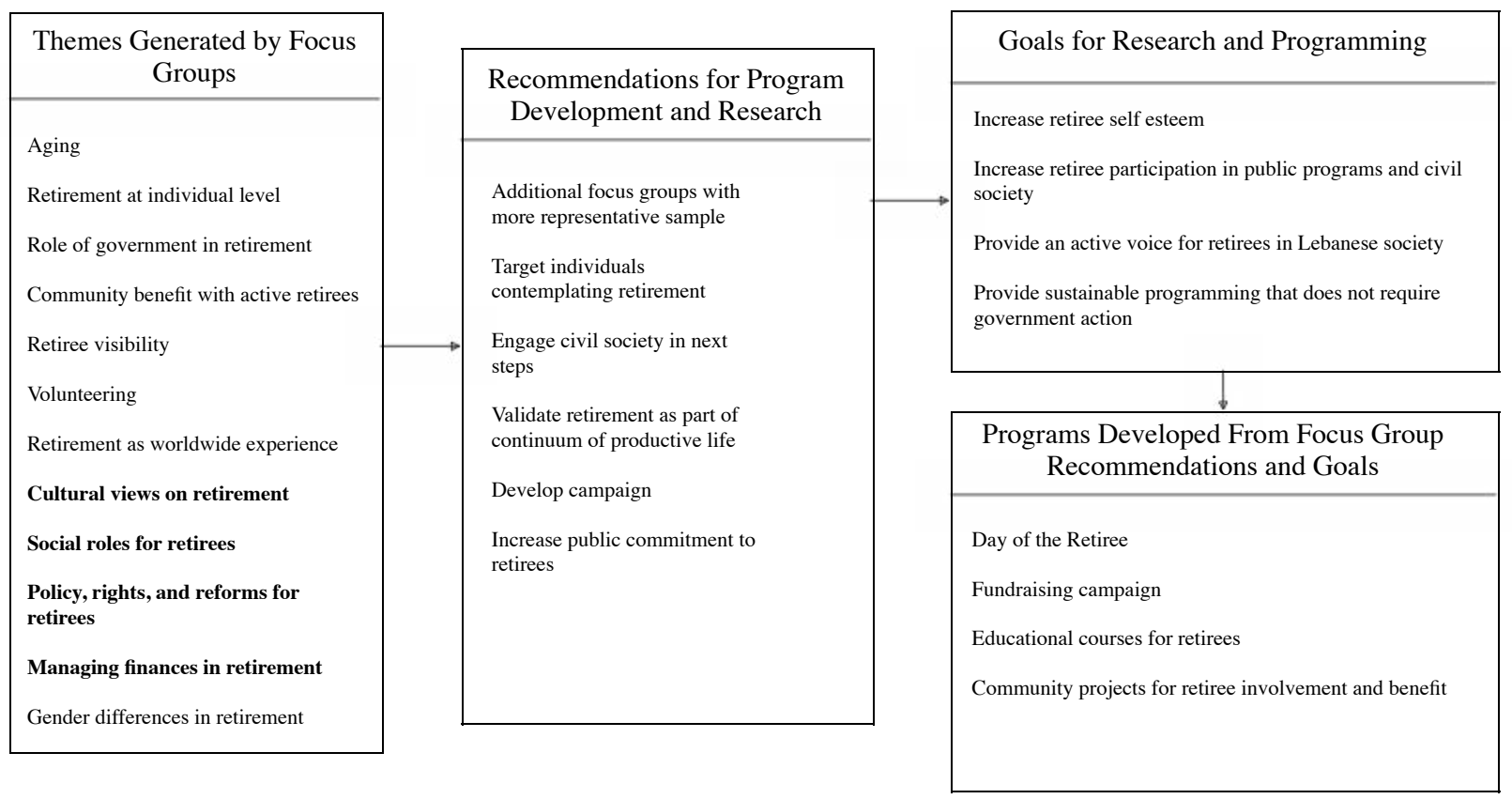

Figure-1. General themes about the nature and challenges of retirement in Lebanon

Note 1: These general themes were stated in the focus groups. Themes were translated into recommendations and goals for future programming, resources, and legislature in Lebanon for retirees. Programming developed as a result of the focus group was included in this model.

Note 2: Bolded text indicates theme discussed by both focus groups.

fulfilling retirement phase where retirees are financially independent.

\section{Fundraising}

Civil society groups, private donors, and the government also collaborated to implement a staged fundraising campaign. The purpose of the fundraising campaign was to raise money to help implement a national program for retiree engagement in multiple municipalities in Lebanon. The fundraising campaign collected a total of $\$ 46.000$ (USD). This money would help augment the $\$ 12.000$ (USD) a year that municipalities are participating in the pilot program already received annually from the Lebanese Ministry of Internal Affairs to spend on local projects.

\section{Education Courses}

Prior to the start of the development project planning process, region retirees attended presentations to help them better prepare for life during retirement. These presentations were conducted by medical professionals, financial advisors, and occupational therapists. Presentation topics for the retirement community included wellbeing, healthy aging, productive time management, as well as managing finances in retirement. These courses were provided in part to meet the retirees' desire to receive education for planning retirement as well as to help provide information for community leaders to inform the pilot projects.

\section{Pillot Development Programs}

This arm of the program was conducted in six municipalities located in five regions of Lebanon (Table-2). Lebanon is divided into six mohafazat: Beirut, Mount Lebanon, North Lebanon, South Lebanon, Bekaa, and Nabatieh. In February of 2015, representatives from $\mathrm{NGO}$ civil society donors Likaa el Athnayn, MOSA staff, members of the municipal councils, and four retirees (two men and two women) in each municipality were selected to plan, engage their communities, and oversee the implementation of chosen pilot development projects to help promote retiree engagement within the community. Money raised in the fundraising portion of the program was used to help the municipalities cover the cost of their projects. 
Each municipality that participated in the pilot development project portion of the study developed a program that was implemented in the communities (Table-2). turns that are concrete and easily measured and those that are less tangible but may hold crucial cultural relevance (Figure-2).

Table-2. Completion status of pilot development programs by region and municipality

\begin{tabular}{|c|c|c|c|}
\hline Region & $\begin{array}{l}\text { Municipal- } \\
\text { ity }\end{array}$ & Program & $\begin{array}{l}\text { Phases of comple- } \\
\text { tion }\end{array}$ \\
\hline North & Halba & $\begin{array}{l}\text { Established agricultural coop, irrigation tools, and farmland to grow crops. } \\
\text { Crops sold at a lower price to retirees and non-retirees paid full price. Full } \\
\text { price lower than the regular market price to make coop produce more lu- } \\
\text { crative in the community. }\end{array}$ & $\begin{array}{l}\text { Completed and } \\
\text { launched }\end{array}$ \\
\hline North & Zgharta & $\begin{array}{l}\text { Committee established a retiree club and education center. Started educa- } \\
\text { tion workshops by retirees for retirees and the public. Workshops based on } \\
\text { the teaching retiree's interest and specialty. }\end{array}$ & $\begin{array}{l}\text { Completed and } \\
\text { launched }\end{array}$ \\
\hline Chouf & Amateur & $\begin{array}{l}\text { Established a retiree club and local meeting place for social gatherings or } \\
\text { for study. Aimed at increasing socialization and to provide opportunities for } \\
\text { retirees to work on projects and be consultants on community projects. }\end{array}$ & $\begin{array}{l}\text { Completed and } \\
\text { launched }\end{array}$ \\
\hline Bekaa & Rachaya & $\begin{array}{l}\text { Bus purchased to help retirees conduct business within the region and out- } \\
\text { side of the municipality. The aim was to expand the capacity for retirees to } \\
\text { be productive and involved with various projects taking place in the region. }\end{array}$ & $\begin{array}{l}\text { Completed and } \\
\text { launched }\end{array}$ \\
\hline South & Nabatieh & $\begin{array}{l}\text { Constructed a sports club for members of the community, including retir- } \\
\text { ees. Membership for community members to the club was free to individ- } \\
\text { uals who wished to be physically active but had limited financial resources. }\end{array}$ & $\begin{array}{l}\text { Completed and } \\
\text { launched }\end{array}$ \\
\hline $\begin{array}{l}\text { Mount } \\
\text { Lebanon }\end{array}$ & Jounieh & $\begin{array}{l}\text { Constructed a retiree club for social gatherings, studying, and community } \\
\text { projects. Prioritized the work of retirees on aspects of local urban develop- } \\
\text { ment projects and expansion. }\end{array}$ & $\begin{array}{l}\text { Construction plans } \\
\text { completed. Awaiting } \\
\text { contractors bids }\end{array}$ \\
\hline
\end{tabular}

\section{Conceptual Framework for a New Social Reality for Lebanese Retirees}

The current literature on the economic pitfalls of retirement in Lebanon and the results of the focus group generated new ideas to explore in the field and advanced a conceptual framework for developing a healthy retirement culture in the country (Figure-2). The top part of the model outlines potential investments that could be made by civil society in retirees. These investments fall into three categories: socio-cultural, health, and economical. Within these categories are suggestions generated by the focus groups and the literature on retirement in Lebanon. On either side of this "investment funnel" are those challenges that limit and restrict the investment potential in retirees and development of retirement culture. Limiting factors fall into the category of "socio-cultural" and "economic." The amount of investment directed into the development of a positive retirement culture in Lebanon then yields potential returns. These benefits fall on a spectrum of tangible re-

\section{Potential Benefits Through the New Con- cept of "Culture of Retirement"}

Increased integration of retirees into Lebanese civil society could have meaningful impacts, both tangible and intangible across the country. Preliminary data highlighted the desire of retirees to be more productive members of society. These benefits have been integrated into the conceptual model and are presented from most tangible to most intangible.

\section{Involvement with national and local service}

Though no longer working in a profession, retirees may still remain a source of assistance in communities. Lebanon is currently a leader economically in the Middle East and North Africa (MENA) region and has one of the largest retiree communities in the area (Abdulrahim et al., 2014; Saadeh \& Mikhael, 2016). Investments in retirees, which mobilize them as a demographic with the potential for economic productivity, may ultimately advance the country's financial growth, rather 
Journal of Aging and Long-Term Care

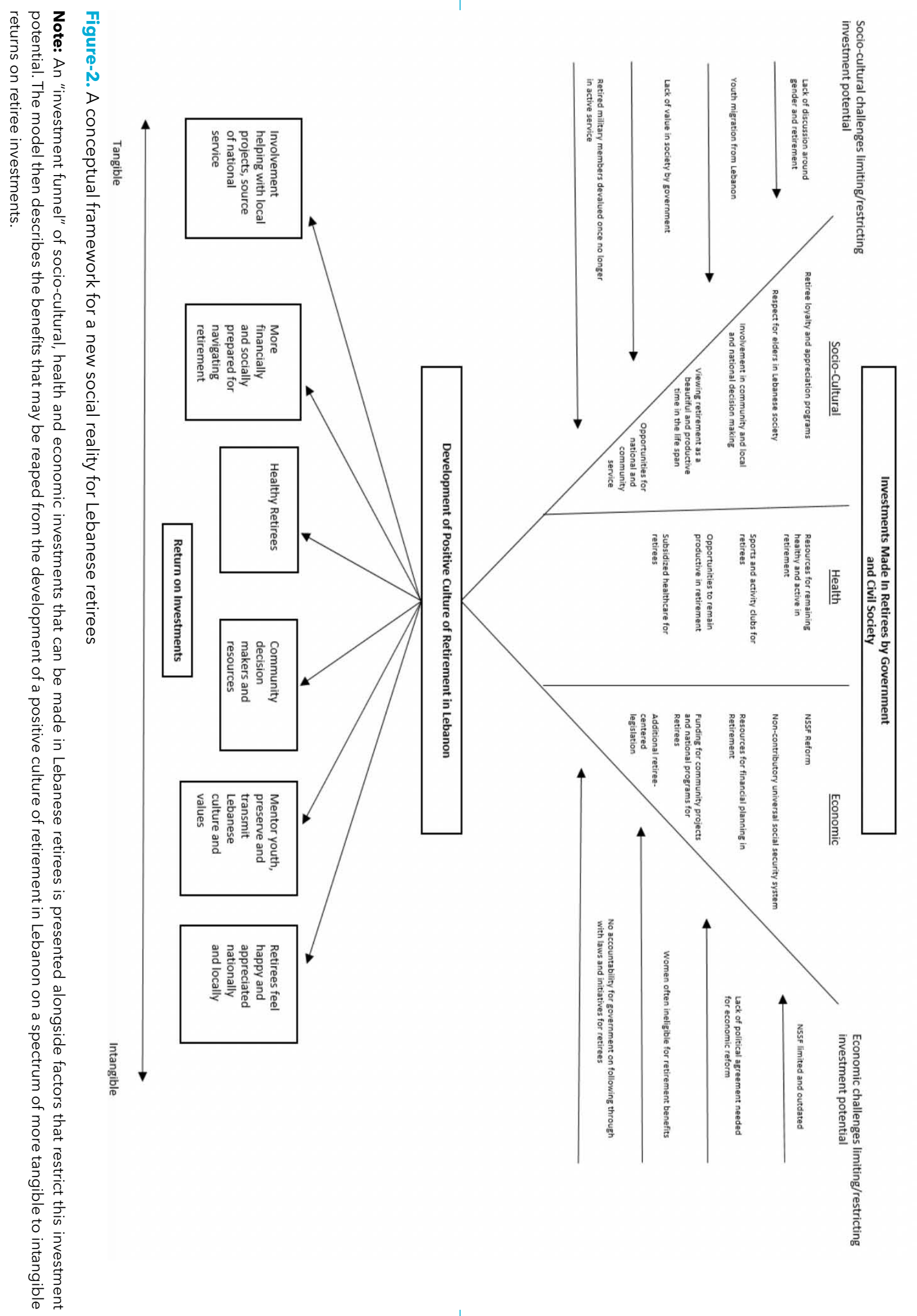


than hinder it due to the cost of this type of social investment.

\section{Better financially and mentally prepared for navigating retirement}

Currently, there is no foreseeable change to the structure and purpose of the NSSF. While awaiting the reforms, in lieu of a stagnant social insurance system, educational courses and materials for individuals nearing and in retirement to promote health and financial planning may be a useful start and meaningful measure in aiding retirees. Even simple resources to help retirees remain active and healthy during retirement and able to navigate the costs that increase during that phase of life, such as health care, could have the potential to improve retiree quality of life and potential for productivity significantly. Future public health research on this demographic can better determine what resources would be most effective in promoting retiree health and financial management acumen. These types of public policy measures require less enactment of political agreement as well as little economic restructuring at the national level (National Social Security Fund).

\section{Opportunities to collaborate with the international community}

The international community can help Lebanon with developmental programs targeting the preparation for retirement (Sayed \& Robalino, 2009). While they continue to await Lebanon's partnership, in their mutual trades with the Lebanese government, the international community and economic donors and players could enforce that such plans are conducted on the ground for the procurement of a stronger social protection net and stabilized economy in Lebanon. This, in fact, would work as an incentive for Lebanon to ensure that its government abides by basic international employment and retirement law and hence benefit from more funding. In return, the international community will benefit from a stable and prosperous Lebanese economy.

\section{Community resources, mentors, and cultural transmitters}

On a local level, mutual benefits to retirees and Lebanese civil society through a new collabora- tive era may not be tangible or always quantifiable. Yet, these benefits may nonetheless be culturally impactful. In the focus groups, retirees expressed that the potential to mentor youth in their communities was important to them. The retirees recognized they might have a unique role to play in both preserving and transmitting Lebanese culture and values to younger generations. Lebanon is experiencing rapid demographic shifts, particularly in younger generations. Caring for members of society who no longer work has been a longstanding cultural value in Lebanon and a source of pride (Abdulrahim et al., 2014). However, this type of respect is not felt in the way the government treats retirees. Acknowledging the prevailing cultural tendency to view retirees as individuals with wisdom, insight, and leadership may strengthen national pride and adherence to social values across age groups. Initiatives from civil society to bolster this positive attitude could be done by tapping into local NGOs and committed Lebanese activists.

\section{Retirees feel happy and appreciated}

An easily overlooked benefit of addressing the pitfalls of retirement culture in Lebanon per the focus group data is that retiree self-perception may likely improve with a societal shift. It will boost their morale, giving them a sense of value and self-confidence and impact positively on their wellbeing and quality of life. Previously discussed benefits have focused primarily on harnessing retiree potential for improving Lebanese civil society as a whole. Some reluctance in trusting the Lebanese government's ability to deliver on policies to benefit retirees stemmed from the belief that it does not prioritize the appreciation and comfort of retirees. Feeling appreciated and that policies for retirees were in the interest of forwarding their vision of retirement was of deep personal significance to those in the focus group

\section{Limitations of the New Concept}

These efforts to explore effective pathways for creating a positive culture of retirement in Lebanon have been some of the first of their kind in the country. However, significant limitations did 
exist with this project that requires further research into the lives and needs of retirees. One of the critical limitations of this work was that the focus groups were made up of former civil servants and military officials. All those interviewed for the focus groups were among the minority of Lebanese retirees who were eligible for a lifetime, ensured pension plans from the government due to their employment in the public sector.

Information provided about the needs of retirees may have been biased by the sample being relatively privileged benefits-wise compared to retirees from the private sector. For these individuals, themes in the groups focused primarily on improved quality of life, cultural appreciation, and more significant investment from the government in the productivity of retirees. Data from a more representative sample of retirees may have yielded different results and priorities for improving the challenges associated with retirement in Lebanon. Additionally, the focus groups were comprised of almost entirely men. Women retirees themselves were not sharing their experiences in retirement, though gender was stated as a critical issue in the focus groups. The selection of participants was not under the control of the author, who led the group. Further research with an economically representative sample and greater gender representation is needed for future studies, particularly on women in retirement or who have a spouse in retirement if they themselves have not worked. Focus groups or qualitative interviews targeting the retirement experience of women might better clarify what specific programs would most benefit this demographic in Lebanon.

For continuing research and community programming to promote retiree wellbeing, pre and post measures should be taken to quantify better and characterize the changes taking place as a result of these programs. Prior to the pilot development projects, no data regarding the status of and attitudes towards retirees was gauged by the study team and collaborators. Data were not collected during or after the implementation of the projects to measure the effectiveness of these programs in meeting their stated goals. Measures of retiree satisfaction with the government before and af- ter new programming, preferences surrounding programming, changes in the way non-retirees perceive retirees after programming is implemented, and the health outcomes of retirees in communities with more significant opportunities for retirees could all serve as possible ways to track significant changes in the culture of retirement in Lebanon.

As a healthy retirement culture is streamlined, it would be in the interest of researchers and civil society leaders to expand their focus to the period of time spent in preparation for retirement. Retirees may be better served to receive resources that allow them to plan ahead of time for their health and financial wellbeing. At present, members of the private sector tend to be cut off very quickly from their NSSF benefits the moment they retire. Viewing individuals five years prior to retirement as part of the target group for social resources and programming might help provide a "head start" in preparing for a stable and productive life after employment. These resources might include financial planning courses, checklists for retirement preparation, embracing community volunteer work prior to retirement, or retiree led talks for soon to be retirees in their communities.

\section{Conclusion}

Many challenges currently inhibit retirees in Lebanon from feeling supported by the Lebanese government and civil society. However, with specific types of investment in the social and economic wellbeing as well as in the health of retirees, the Lebanese society as a whole may benefit from a happier, more active, engaged, and visible retiree population. Moreover, we find the conceptual model of "retirement culture" could strengthen the values of intergenerational work, increase and empower collaboration between civil society and the government. Ideally, the current efforts that have been made to develop a healthy culture of retirement in Lebanon will be disseminated throughout the country and serve in a more extensive global dialog on how to best support retirees in the MENA region and/or other middle-income countries. 
Acknowledgments: The authors would like to thank the Lebanese Ministry of Social Affairs Staff, especially the family Unit Staff, for their invitation and their generous human resources support. Without them, this work could not see the light. Special thanks to Ms. Dalale Doueihi, senior social worker, who started and developed the culture of retirement within the ministry and across Lebanon and continues to work diligently pushing frontiers and barriers related to this topic.

\section{References}

Abdulrahim, S., Ajrouch, K. J., \& Antonucci, T. C. (2014). Aging in Lebanon: Challenges and opportunities. The Gerontologist, 55(4), 511-518.

BBC (2019, 21.10.2019). Lebanon Protests: Huge Crowds on Streets as Government Acts. Retrieved from https://www.bbc.com/news/world-middle-east-50118300

CAS (The Central Administration of Statistics) (2019). Lebanese Republic: The Presidency of the Council of Ministers, The Central Administration of Statistics. Retrieved from http://www.cas.gov.lb/

Hamade, A. S. H., Ghobeira, M. G., \& Yassin, N. (2015). Assessing the Lebanese Elderly Welfare Pension Reform: Time for a New Policy: American University of Beirut

ILO (International Labor Organization) (2013, 20.05.2013). Lebanon's Long Awaited Pension Reform Within Reach. Retrieved from http://www. oit.org/global/about-the-ilo/newsroom/features/ WCMS_207664/lang--en/index.htm

Jarmuzek, M., \& Nakhle, N. (2016). Sustainability and Equity Challenges; Some Arithmetic on Lebanon's Pension System: International Monetary Fund.

MENA Group (World Bank Middle East and North Africa Social and Economic Development Group) (2009). The Status and Progress of Women in the Middle East \& North Africa. Washington, DC: World Bank Middle East and North Africa Social and Economic Development Group.

Munyambonera, E., Katunze, M., Munu, M. L., \& Sserunjogi, B. (2018). Expanding the Pension Sector in Uganda (Report No: 677-2018-5024).

Rached, M. (2012). Social Security in Pensions in Lebanon: A Non-Contributory Proposal. Beirut, Lebanon: Lebanese Economic Association.
ReliefWeb (2017, 31 Dec 2017). Lebanon Humanitarian Fund - Annual Report 2017. Retrieved from https://reliefweb.int/report/lebanon/lebanon-humanitarian-fund-annual-report-2017

Saadeh, L., \& Mikhael, M. (2016). Lebanon's Pension System Beirut, Lebanon: Blominvest Bank.

Saxena, P. C. (2008). Ageing and age-structural transition in the Arab countries: Regional variations, socioeconomic consequences and social security. Genus, 37-74.

Sayed, H., \& Robalino, D. (2009). Lebanon: Moving Forward With Pension Reform in Lebanon. In H. Larbi (Ed.), The Financial Crisis: Impact on the Middle East (No: 57793) (pp. 12-16). Washington, DC: The World Bank Middle East Department.

Sibai, A. M. (2000). The elderly in Lebanon In The status of disadvantaged population groups in LebanonPopulation and Housing Survey. Beirut: Ministry of Social Affairs and UNDP (pp. 48-124). Beirut, Lebanon.

Sibai, A. M., Sen, K., Baydoun, M., \& Saxena, P. (2004). Population ageing in Lebanon: current status, future prospects and implications for policy. Bulletin of the World Health Organization, 82, 219-225.

Sibai, A. M., Yount, K., \& Fletcher, A. (2007). Marital status and living arrangements as predictors of mortality among middle-aged and older men and women during wartime in Beirut: Gains and liabilities. Social Science and Medicine, 64(1), 64-76.

SSA (Social Security Administration) (2010). Social security programs throughout the world: Asia and the Pacific, 2010. Retrieved from https://www.ssa.gov/ policy/docs/progdesc/ssptw/2010-2011/asia/lebanon.html

SSA (Social Security Administration) (2017). Social Security Programs Throughout the World: Africa, 2017 (Publication No. 13-11803). Washington, DC Social Security Administration Office of Retirement and Disability Policy Office of Research, Evaluation, and Statistics.

Star, T. D. (2017, 23.07.2017). Protesters Decry Tax Increases in Downtown Beirut. Retrieved from http:// www.dailystar.com.lb/News/Lebanon-News/2017/ Jul-23/413680-protesters-decry-tax-increases-in-downtown-beirut.ashx

Tohme, R. A., Yount, K. M., Yassine, S., Shideed, O., \& Sibai, A. M. (2011). Socioeconomic resources and living arrangements of older adults in Lebanon: who chooses to live alone? Ageing \& Society, 31(1), 1-17. Crossref 